\title{
Herding and Contrarian Behavior in Financial Markets: An Internet Experiment
}

\author{
By Mathias Drehmann, Jörg Oechssler, and Andreas Roider*
}

\begin{abstract}
We report results of an Internet experiment designed to test the theory of informational cascades in financial markets (Christopher Avery and Peter Zemsky, 1998). More than 6,400 subjects, including a subsample of 267 consultants from an international consulting firm, participated in the experiment. We find that the presence of a flexible market price prevents herding. The presence of contrarian behavior distorts prices, however, and even after 20 decisions, convergence to the fundamental value is rare. We also report some interesting differences with respect to subjects' fields of study. Reassuringly, the behavior of the consultants turns out to be not significantly different from that of the remaining subjects. (JEL C92, D8, G1)
\end{abstract}

While the popular press often blames "lemminglike" behavior of investors for the observed exuberance in financial markets, the question whether herding actually occurs in real financial markets remains, for various reasons, very dif-

\footnotetext{
* Drehmann: Bank of England, Threadneedle Street, London EC2R 8AH, UK (e-mail: mathias.drehmann@ bankofengland.co.uk); Oechssler: Department of Economics, University of Heidelberg, Grabengasse 14, 69117 Heidelberg, Germany, (e-mail: oechssler@uni-hd.de); Roider: Department of Economics, University of Bonn, Adenauerallee 24-42, 53113 Bonn, Germany (e-mail: roider@uni-bonn.de). We are grateful to Jörg Breitung, David Easley, John Morgan, Georg Nöldeke, Erik Theissen, Georg Weizsäcker, and Anthony Ziegelmeyer for suggestions, and to Doug Bernheim and three referees for extensive and very helpful comments. We also thank seminar participants in Amsterdam, Bonn, Frankfurt, Mannheim, Munich, Zurich, at Harvard University, New York University, WHU, the ES Winter Meeting 2004 in San Diego, the Royal Economic Society meetings 2003 in Warwick, the EEA meetings 2003 in Stockholm, the ESA meetings 2002 in Strasbourg, and the ENDEAR meetings 2002 in Jena for lively discussions and suggestions. We thank Frauke Lammers, Susanne Niethen, and Nina Wessels for very helpful discussions throughout the project, and McKinsey \& Company for financial support. We also thank the Laboratory for Experimental Research in Economics at the University of Bonn, the Bonn Graduate School in Economics, and Deutsche Forschungsgemeinschaft, through SFB/TR 15. The third author gratefully acknowledges a research fellowship by the Deutsche Forschungsgemeinschaft. Finally, we are very grateful to Ben Greiner who did an excellent job programming the experiment. This paper was part of Mathias Drehmann's Ph.D. thesis at the University of Bonn. It represents the analysis and views of the authors and should not be thought to represent those of the Bank of England or Monetary Policy Committee members.
}

ficult to resolve with field data. When investors are observed taking the same action, this may be due to herding. But it may also be caused by investors following the same information, or the clustering of actions may simply be incidental. In empirical work, those explanations are difficult to disentangle, since the private information of investors is, in general, unobservable. In order to contribute to this question, we conducted a large-scale Internet experiment based on a sequential asset market as described by Avery and Zemsky (1998). An experiment offers an opportunity to test herding theories directly, since all fundamentals and the private information of agents are under control of the experimenter.

Several sources of rational herding are known in the theoretical literature. For example, when market participants' payoffs depend directly on the behavior of others, herd behavior is natural. Such payoff externalities cause herding of analysts or fund managers in models of reputational herding (e.g., David Scharfstein and Jeremy C. Stein, 1990), or herd behavior of depositors in bank runs (e.g., Douglas Diamond and Philip Dybvig, 1983). ${ }^{1}$ Even if such payoff externalities are absent, however, herd behavior may be observed in markets through a process of information transmission. Models based purely on informational externalities were pioneered by

\footnotetext{
${ }^{1}$ Within our experiment, we also implemented treatments designed to test the effects of reputation and payoff externalities in herding decisions. We report on these treatments in a companion paper (Drehmann et al., 2004).
} 
Abhijit V. Banerjee (1992), Sushil Bikhchandani et al. (1992) (henceforth BHW), and Ivo Welch (1992). An informational cascade is said to occur when it becomes rational to ignore one's own private information and instead follow the predecessors' decisions. Since no further information is revealed once an informational cascade has started, inefficiencies occur even though each individual is behaving rationally.

Theories of rational herding or informational cascades are, however, not directly applicable to financial markets. Market prices are a powerful mechanism which, in theory, efficiently aggregates private information of traders. In particular, Avery and Zemsky (1998) (henceforth AZ) have shown that informational cascades cannot occur in a simple sequential asset market because a flexible market price incorporates all publicly available information. As traders receive private information, they have an informational advantage over the market maker. Thus, rational traders should always follow their private signal and thereby reveal their information. ${ }^{2}$ Note that in this class of sequential trade models, traders are allowed to buy or sell only once, and therefore classical price bubbles driven by traders, who think they can resell the asset before the bubble bursts, are not possible. ${ }^{3}$

In reality, herding may nevertheless occur due to the likely existence of boundedly rational traders who may be plagued by a variety of biases and follow more or less plausible rules of thumb. Imitation, trend chasing, momentum trading strategies, and the like are possible alternative sources for herd behavior in financial markets. Finally, there are strategies advocated by popular guide books and analysts that should

\footnotetext{
${ }^{2} \mathrm{AZ}$ show that herding may occur in the presence of multidimensional uncertainty, even though informational cascades remain impossible. See also Marco Cipriani and Antonio Guarino (2001), who show that informational cascades are possible if agents are heterogeneous such that gains from trade exist.

${ }^{3}$ For a survey of theories of rational bubbles and herding, see, e.g., Markus Brunnermeier (2001). For a survey of experimental research on bubbles in asset markets, see, e.g., Shyam Sunder (1995). For recent work in this area, see, e.g., Cars Hommes et al. (2002), or John Hey and Andrea Morone (2004).
}

counteract herd behavior. ${ }^{4}$ In particular, "contrarian" or "value strategies" call for buying assets with low prices relative to some fundamental value like earnings, dividends, historical prices, etc. (For empirical evidence on the profitability of such strategies, see, e.g., Josef Lakonishok et al., 1994, or Rafael La Porta et al., 1997.)

The Internet experiment we report on in this paper was designed to address the following objectives. First, we want to test the theory of informational cascades in financial markets as introduced by AZ by taking the theory at face value. To have the potential to reject their theory, we implement a design that exactly matches their theoretical setup. The main test for this theory is whether herding is actually prevented by market prices. Second, we are interested in filtering out empirical regularities that may explain possible deviations from the theory. In particular, we want to find out whether traders follow their own signal (which is rational if all others are rational, too), whether they engage in herd behavior, or whether they follow contrarian strategies by trading against their signal and the market. Third, we use the variety and size of our subject pool to detect possible differences in subjects' behavior as a function of their personal characteristics. Chief among those is the question whether businessmen behave differently from college students, who are usually used in experiments. For this purpose, we conducted a control experiment with 267 consultants from McKinsey \& Company, Inc., an international consulting firm.

More than 6,400 subjects participated in our experiment, in which a substantial amount of prize money was at stake. The subject pool was exceptionally educated, with more than 13 percent holding a Ph.D. degree and another 30 percent being Ph.D. students. Almost half the subjects were educated in natural sciences, mathematics, or engineering. The main treatments in this experiment were variants of the basic model by AZ in which a market price aggregates all publicly available information. Traders received a private signal and could observe the history of prices and, in most treat-

\footnotetext{
${ }^{4}$ See, e.g., the investment classic Contrarian Investment Strategies by David Dreman (1979, 1998), or his column "The Contrarian" in Forbes Magazine.
} 
ments, the decisions of their predecessors. The large number of participants in the experiment allowed us to introduce a variety of modifications of the basic model. For example, we explored many different combinations of a priori probabilities and signal precisions to check for robustness.

As mentioned above, in our main treatments we aimed at matching AZ's theoretical setup exactly. Thus, when setting prices, the market maker (which in the experiment was played by the computer) assumed that all subjects behaved rationally. In the course of the experiment, it emerged, however, that a substantial fraction of subjects did not follow their own signal. A human market maker in a real market would presumably learn this over time and adjust his pricing behavior accordingly. ${ }^{5}$ As a consequence, we studied two additional "error" treatments, where the market makers' price-setting rule was modified to account for the fact that subjects do not always adhere to their signals. The first of these treatments is in the spirit of the literature on noise traders. In this treatment the market maker assumed that, in addition to rational traders, there is a fixed proportion of noise traders, whose decisions are uninformative. In the second "error" treatment, building on the notion of quantal response equilibrium of Richard D. McKelvey and Thomas R. Palfrey (1995, 1998), the market maker based his pricing behavior on the assumption that the propensity to follow one's own signal might depend on the history of previous decisions.

Finally, for comparison, we studied two benchmarks. First, we conducted treatments without market prices corresponding to the basic model of BHW. Second, another important benchmark is treatments in which subjects could observe not only the decisions of their predecessors but also their private signals. In those treatments, doubts about the rationality of others cannot be an issue.

Our experiment complements a large empirical literature with field data. Beginning with Lakonishok et al. (1992), researchers were analyzing the tendency of fund managers, security analysts (Welch, 2000), or investment newsletters (John R. Graham, 1999) to herd (for sur-

\footnotetext{
${ }^{5}$ We thank the co-editor Douglas Bernheim for pointing this out.
}

veys, see, e.g., Bikhchandani and Sunil Sharma, 2000; Kent Daniel et al., 2002; or David Hirshleifer and Siew Hong Teoh, 2003). However, as Hirshleifer and Teoh (2003) note, it will always be difficult to empirically disentangle the mixture of reputational effects, informational effects, direct payoff externalities, and imperfect rationality.

Following Lisa R. Anderson and Charles A. Holt (1997), there is by now a well-established experimental literature on cascade and herding models. ${ }^{6}$ To our knowledge, however, there is only one other experiment on cascades in financial markets with flexible prices (conducted by Cipriani and Guarino, 2005). Some of our treatments are very close to their experiment, and we will comment at several places in this paper on their results. ${ }^{7}$

Our paper is structured as follows. In Section I, we first discuss the theoretical predictions for the basic BHW model without prices, and then for the AZ model with market prices. In Section II, we describe the experimental design, in particular the different treatments, the recruitment, the characteristics of the subject pool, and the implementation on the Internet. ${ }^{8}$

The results of the experiment are presented in Section III. Perhaps the most important result is that we find no evidence of herding or imitative

\footnotetext{
${ }^{6}$ See, e.g., Robert Goidel and Todd Shields (1994), Kene Bounmy et al. (1998), Marc Willinger and Anthony Ziegelmeyer (1998), Louise Allsopp and Hey (1999), Klarita Sadiraj et al. (1999), Steffen Huck and Oechssler (2000), Masahiro Ashiya and Takero Doi (2001), Angela Hung and Charles Plott (2001), Markus Nöth et al. (1999), Clemens Oberhammer and Andreas Stiehler (2001), Nöth and Martin Weber (2003), Plott et al. (2003), Dorothea Kübler and Georg Weizsäcker (2004), and Carlo Krämer et al. (2005).

${ }^{7}$ Cipriani and Guarino (2005) conducted a paper-andpencil experiment with a $50-70$ probability combination and 12 traders in a group. When we conducted our experiment, we were not aware of their experiment. It is clear, however, that their experiment has precedence. In our notation (see Table 1) they ran treatments that are comparable to $P+D, P-D$, BHW, and an additional treatment in which two subjects acted as market makers.

${ }^{8}$ Conducting experiments on the Internet is still novel. For first experiences, see, e.g., Robert Forsythe et al. (1992, 1999), David Lucking-Reiley (1999), Vital Anderhub et al. (2001), Gary Charness et al. (2001), Tal Shavit et al. (2001), Antoni Bosch-Domenech et al. (2002), and Werner Güth et al. (2003). For technical issues, see, e.g., Ben Greiner et al. (2003). The Internet is also used to provide a platform to run economic experiments for interactive learning (Holt, forthcoming).
} 
behavior in the presence of a flexible market price. While this aspect is consistent with the AZ model, other theoretical predictions of the AZ model find no support in the data. Recall that the AZ model predicts that all subjects follow their private information. In the experiment, this happens only in between 50 percent and 70 percent of cases. Clearly, such behavior yields substantial deviations of actual prices from full information prices that would be obtained if everyone behaved rationally. We find that, on average, actual prices are less extreme than full information prices, which implies that volatility in the actual market is lower than it should be theoretically. While we do not observe herding, we find considerable support for the existence of "contrarian" behavior. When the price of asset $A$ is high, subjects often buy asset $B$, even if their own private information and the decisions of their predecessors favor asset $A$, and vice versa. Since we find that contrarian behavior can be profitable at very low or very high prices, we explore the possibility that subjects have doubts about the rationality of others, and consequently mistrust their decisions. We find that error models (like the quantal response models of McKelvey and Palfrey, 1995 and 1998), which explicitly take into account the possibility of mistakes, are partly able to rationalize contrarian behavior.

The large number of participants allows us to further conduct a number of interesting comparisons of behavior with respect to demographics, fields of studies, etc. There seems to be no significant difference between male and female subjects, or between subjects with and without a college education. Subjects holding a Ph.D. degree, however, are slightly more in line with theoretical predictions. Maybe it does not come as a surprise that when we look at selected fields of study, physicists perform the best in terms of "rationality" (i.e., performance according to theory) and psychologists the worst. However, since "rational" behavior is profitable only when other subjects behave rationally as well, good performance in terms of "rationality" does not imply good performance in terms of profits. Indeed, the ranking in terms of profits is just the opposite: psychologists are the best and physicists the worst. Finally, it is reassuring that the consultants in our control experiment did not behave significantly different from the subjects in the main experiment, which is important for the outside validity of our experiment. Section IV contains a conclusion. The various appendices mentioned below are available on the AER Web site (http://www.e-aer.org/dec05_app_ oechssler.pdf).

\section{Theoretical Predictions}

Consider a number of investors who have to decide sequentially whether to invest in one of two assets, $A$ or $B$. For simplicity, each investor can buy only one unit of asset $A$ or one unit of asset $B$ (sometimes we also allow for the possibility that no trade occurs). Investors are risk neutral and have the same a priori beliefs regarding the probabilities of success of the two investments. Specifically, only one asset is successful and worth ten units at the end of the period, while the other is worth zero. The successful asset is determined at the beginning of the experiment and each investor knows the a priori probability that asset $S$ is successful, $P(S)$, $S \in\{A, B\}$.

The timing is as follows. Investors move sequentially in some exogenous order, with each investor moving only once. Before deciding what to buy, each investor receives a private, informative signal $a$ or $b$ regarding the success of the assets. The signal's precision is $P(a \mid A)=$ $P(b \mid B)>0.5$, which is the conditional probability that signal $s \in\{a, b\}$ occurs, given the true state is $S \in\{A, B\}$. For all investors, the signal is identically and independently distributed conditional on the true state. This is commonly known. Each investor can observe the decisions of all his predecessors.

We consider two principal versions of this model: one in which the price of the two assets is fixed (and set equal to zero for simplicity) and one in which the prices of $A$ and $B$ are market prices that reflect publicly available information. The version with zero prices is equivalent to the basic model studied by BHW. The model with market prices has been studied by AZ.

\section{A. The BHW Model}

All investors can invest either in asset $A$ or $B$-but not both—at zero cost. ${ }^{9}$ Clearly, an in-

\footnotetext{
${ }^{9}$ Introducing a fixed price would not alter the strategic setting.
} 
vestor with $t$ predecessors will choose $A$ if and only if the conditional probability that $A$ is successful given all private and public information $P\left(A \mid H_{t}, s\right)$ is greater than $1 / 2,{ }^{10}$ where $H_{t}$ denotes the observable history of the decisions of all predecessors up to round $t$, and $s=a, b$ the private signal.

The difficulty lies in the interpretation of decisions of predecessors. Assuming that all predecessors are perfectly rational Bayesians, an investor who is a Bayesian himself follows his private signal and thereby reveals it, unless an informational cascade has started. If a signal can be deduced from the chosen action, it is called an imputed signal.

A cascade on asset $S$, an $S$-cascade, starts when an investor should buy asset $S$ regardless of his own signal, i.e., when $P\left(S \mid H_{t}, s\right)>1 / 2$, for $s=a, b$. Depending on the a priori probabilities and the signal precisions, this requires a certain number of (imputed) $a$ or $b$ signals. In all cases, however, the onset of a cascade depends only on the net number of $a$-signals $\Delta=\# a-\# b$ that can be imputed from the history of decisions (i.e., $\Delta$ is defined net of the signal of the current investor).

We demonstrate the calculations for our main probability combination 55-60, that is, $P(A)=$ 0.55 and $P(a \mid A)=P(b \mid B)=0.6$. The first investor should always follow his own signal since even if he receives a $b$-signal, $P(B \mid b)=$ $1-P(A \mid b)>1 / 2$ holds. Hence, the signal of the first player can be imputed from his action. If the first investor chooses $A$, the second should already disregard his own signal: even with a $b$ signal, the second investor should choose $A$ since

$$
\begin{aligned}
P(A \mid a b) & =\frac{P(a b \mid A) P(A)}{P(a b \mid A) P(A)+P(a b \mid B) P(B)} \\
& =0.55,
\end{aligned}
$$

which is the a priori probability for $A$. The two signals $a$ and $b$ cancel out and the decision should follow the a priori probability. In this case, the third player cannot impute the signal

\footnotetext{
${ }^{10}$ In most of our treatments, ties in expected profit cannot occur. When a tie-breaking rule is required, it is explicitly mentioned below.
}

of the second player and thus faces a similar decision problem as the second player. Hence, after one $A$, an $A$-cascade starts, i.e., when $\Delta \geq$ 1. Likewise, it can be shown that a $B$-cascade must start for $\Delta \leq-2$. If all agents are rational Bayesians, a cascade is never broken once it is started, and information accumulation stops (i.e., $-2 \leq \Delta \leq 1$ at all times unless errors occur).

In an experiment, one can hardly assume that all subjects are rational Bayesians, let alone that all subjects believe that all other subjects are rational. In particular, one has to make provisions for the fact that irrational behavior may be unambiguously observed (as when the second subject chooses $B$ following an $A$ by the first subject in the example above).

To account for possible non-Bayesian behavior, we assume that subjects impute signals in the following way. If there is no history of signals that can explain an observed action, given that all predecessors behaved according to the Bayesian calculus explained above, we say that the action is in "obvious contradiction to Bayes's rule." If a decision is not in obvious contradiction to Bayes's rule, the imputed signal equals the decision unless a cascade has started, in which case no signal can be extracted from the respective decision. For a decision which, given the history of imputed signals, obviously violates Bayes's rule (i.e., if a cascade is broken), we considered two variants: (a) successors ignore the decision of the deviator; and (b) subjects assume that the deviator followed his private signal. As it turns out, the empirical truth lies somewhere in the middle, but both assumptions yield qualitatively the same results. In the following, we report only results based on rule (b). We say that an agent is "rational under common knowledge of rationality" (henceforth: ruck) if he follows Bayesian updating with respect to the imputed signal history and his own signal. In the following, it is important to remember that ruck is based on the assumption that all predecessors are rational. It may be perfectly rational to deviate from ruck if a subject thinks that his predecessors are not rational.

Of course, no ambiguity with regard to rationality arises when not only decisions but also signals of others are observable. In this case, an optimal decision is purely a matter of calculating conditional probabilities. As mentioned 
above, we also consider such a setting in some of our treatments.

\section{B. The Avery/Zemsky Model}

To keep the experiment as simple as possible, we consider the simplest version of the AZ model (cf. Avery and Zemsky, 1998, sect. I), which is the BHW model enriched by a flexible price. In this model, the price is set by a market maker who efficiently incorporates all publicly available information. ${ }^{11}$ The crucial question is how the existence of a market price changes the possibilities for herding.

Let $p_{t}$ denote the market price of asset $A$ in round $t$ and assume, as above, that a successful asset pays out ten units in the end. Hence,

$$
p_{t}=10 P\left(A \mid H_{t}\right) \text {. }
$$

The price of $B$ is always equal to $10-p_{t}$ since $P\left(A \mid H_{t}\right)=1-P\left(B \mid H_{t}\right)$.

The decision of an investor is straightforward. An investment in $A$ is profitable in expectation if and only if

$$
10 P\left(A \mid H_{t}, s\right)-p_{t}>0,
$$

that is, if and only if $s=a$. Likewise, an investment in $B$ is profitable if and only if $s=$ $b$. In other words, each investor follows his private signal. All information is revealed, and therefore it is incorporated into the price immediately after each decision. This implies that the price is semistrong efficient, i.e., at any point in time, the price incorporates all publicly available information. The price is a martingale with respect to public information, i.e., $E\left(p_{t+1} \mid H_{t}\right)=$ $p_{t}$ for all $t$, and one cannot take advantage of the knowledge of historical price movements to earn superior returns. As everyone follows his

\footnotetext{
${ }^{11}$ In contrast to AZ's general model, which is in the spirit of Lawrence Glosten and Paul Milgrom (1985), the simple model does not incorporate uninformed traders, and therefore has no bid-ask spread. With only informed traders, setting a bid-ask spread to ensure a zero profit condition for the market maker would lead to a market breakdown. The results of the simple model, however, carry over to a more complex world with informed and uninformed traders and a market maker setting bid-ask spreads (see AZ, Proposition 3). As in the experiment, the market maker was played by the computer, the possibility of losses was not an issue.
}

signal, rational herding cannot occur. Note that not trading is never optimal (unless one introduces transaction costs) because subjects always have an informational advantage over the market maker.

Again, the problem becomes more complicated when investors cannot be fully confident that their predecessors behaved rationally. Suppose, instead, the investor believes that (some) prior decisions were taken randomly. A regression to the mean argument implies that high prices are likely to be overvalued and low prices undervalued. Thus, it may pay for an investor to trade against the market and against his own signal. Such investors are called contrarians even though rational contrarians would never occur in our setting if all investors were known to be rational.

\section{Experimental Design}

More than 6,400 subjects participated in our online experiment, which was available for a period of about six weeks in 2002 on our Web site, http://www.a-oder-b.de, which is German for $a$-or- $b .{ }^{12}$ Subjects decided in sequence and were able to observe the actual decisions of prior participants in their respective groups. In general, the group size was 20. Subjects were asked to make decisions in three independent groups. We call the first decision stage 1, the second stage 2 , and the third stage 3 . Thus, in total, there were more than 19,000 decisions.

Common to all treatments are the following features. Subjects had to choose between investment opportunities $A$ and $B$. (In some price treatments, there was also the option of choosing neither, which we label $N$.) Only one of the two could be successful and, if so, would pay 10 "Lotto-Euros." The unsuccessful investment paid nothing. Subjects were told the a priori probabilities $P(S)$, which varied among our treatments. Furthermore, they were told that they would receive a tip by an investment banker that was reliable with a specified probability $P(s \mid S)$, which also varied among our treatments. Subjects were informed that all prior investors in their group had received a tip by other investment bankers and that these tips were independent of theirs. (See Web Appendix

\footnotetext{
${ }^{12}$ Some follow-up treatments were run in January 2004.
} 
TABle 1 -TReatments

\begin{tabular}{|c|c|c|}
\hline $\begin{array}{l}\text { Treatment } \\
\text { group }\end{array}$ & Treatment & Description \\
\hline$P$ & $\begin{array}{l}P+D \\
P-D \\
P e+D \\
P t+D\end{array}$ & $\begin{array}{l}\text { Price, all decisions observable } \\
\text { Price, no decisions observable } \\
P+D \text { and explicit formulation } \\
P+D \text { and table to explain pricing rule }\end{array}$ \\
\hline$P-N$ & $\begin{array}{l}P+D-N \\
P-D-N \\
P t+D-N\end{array}$ & $\begin{array}{l}P+D, \text { and } N \text { not possible } \\
P-D \text {, and } N \text { not possible } \\
P+D-N \text { and table to explain pricing rule }\end{array}$ \\
\hline$P-N+\mathrm{AS}$ & $\begin{array}{l}P+\mathrm{AS}+D-N \\
P+\mathrm{AS}-D-N\end{array}$ & $\begin{array}{l}P+D-N \text { and all signals observable } \\
P-D-N \text { and all signals observable }\end{array}$ \\
\hline \multirow[t]{2}{*}{$P-N_{\text {error }}$} & $\begin{array}{l}P f+D-N \\
P \beta+D-N\end{array}$ & $\begin{array}{l}P t+D-N \text { and pricing rule with constant error } \\
P+D-N \text { and pricing rule with variable error }\end{array}$ \\
\hline & $\begin{array}{l}\mathrm{BHW} \\
\mathrm{BHW}+\mathrm{AS}\end{array}$ & $\begin{array}{l}\text { Bikhchandani/Hirshleifer/Welch } \\
\text { BHW and all signals observable }\end{array}$ \\
\hline
\end{tabular}

Note: The symbol $N$ denotes the option of not trading.

A for a translation of the instructions.) In the next subsection, we introduce the details of the different treatments.

\section{A. Treatments}

Given the large number of participants, we were able to explore a variety of different questions, information conditions, probability combinations, etc. In this paper, we focus on treatments that are relevant to financial markets, i.e., treatments that follow the basic setup of AZ, where a market price exists which reflects all publicly available information. In two additional treatments, we deviate from the basic setup by assuming that subjects make errors with some probability, and that the market maker takes this into account. For comparison we also include two treatments without prices which follow the basic model of BHW.

Table 1 lists the main features of all treatments. Names of treatments with market prices start with $P$ followed by $+D$ when, additional to the price history, the decisions of all prior investors are observable, or $-D$ when only the price history is observable. Hence, in treatments $+D$, subjects could observe how decisions influenced prices. A $-N$ denotes treatments in which the "no-trade" option was absent, i.e., subjects were forced to buy either $A$ or $B$.

In our main treatments $P$ and $P-N$, we used the same pricing rule as in AZ. That is, prices were set to reflect all public information that was available at the respective points in time. The computer took the role of the market maker and assumed that all decisions were formed according to ruck (see (2)), i.e., that all subjects followed their own signal, unless this could be unambiguously rejected (which could occur only in case of an irrational no-trade decision). In the latter case, no signal could be imputed, and hence the price remained constant (see Web Appendix B for a detailed description of how prices were formed in each of our treatments).

To explain the pricing rule to subjects is not a simple task. Therefore, we chose several different ways of presenting it. In the main treatment groups $P$ and $P-N$, subjects were told in the instructions that "share prices are determined by supply and demand such that outside investors, who can observe the history of trades but not the tips given by the investment bankers, have no incentive to trade, i.e., an outside investor could not expect to profit from buying or selling one of the shares." In treatments indexed by an ' $e$ ', subjects were told, in addition, that prices are conditional expected values given the history of decisions. ${ }^{13}$

In treatments indexed by ' $t$ ', subjects were

\footnotetext{
${ }^{13}$ We have also used two versions of the instructions, an old and a new version, the latter being more precise about
} 
given a table instead of the explanation via outside investors. This table explicitly listed the price resulting from each possible net number of $A$-decisions by predecessors (i.e., the number of predecessors who chose $A$ minus the number of predecessors who chose $B$ ). The instructions also contained three examples that demonstrated the way the price depended on the net number of $A$ decisions.

The $P-N+$ AS treatments were identical to the corresponding $P-N$ treatments, except that subjects (and the market maker) were also able to observe all signals of predecessors. In those treatments, subjects did not need to worry about the rationality of their predecessors' actions.

If all agents act in line with theory, all of the price treatments above $(P, P-N$, and $P-N+$ AS) have the same theoretical prediction: everyone should follow his own signal. ${ }^{14}$ Whether past decisions are observable or not is irrelevant, since the price history fully reveals past decisions, and the decision history yields no additional information. Furthermore, the notrade option $N$ should not alter the results, because not trading is never optimal.

Up to now, we have assumed that the computer as market maker bases the price on the assumption that subjects follow their signal (as predicted by theory). After running most of the experiment, however, we observed substantial deviations from the theoretical predictions. A human market maker in a real market would presumably learn this over time and adjust his pricing rule. ${ }^{15}$ To check whether the chosen pricing rule biased our results, we introduced two additional "error" treatments in which prices are set under the assumption that subjects sometimes deviate from the theoretical predictions. Treatment $P f+D-N$ is the same as $P t+D-N$, except that price calculations were based on the assumption that each subject

the independence of the investment bankers' tips. See Section III $\mathrm{H}$ for more on this.

${ }^{14}$ In $P-N+$ AS, this holds independent of the behavior of predecessors because the market maker is assumed to be able to observe the signals, and hence in these treatments actual prices equal full information prices (see Section III C).

${ }^{15}$ Interestingly, Cipriani and Guarino (2005) ran a treatment in which the market maker was played by subjects. They find no significant difference to the treatment in which the market maker followed the rule of Avery and Zemsky (1998). chooses only with probability 0.6542 the asset that is consistent with her signal. This probability was based on the empirically observed frequency with which subjects followed their signal in treatments $P-N+\mathrm{AS}$ (in which there was no need to worry about rationality of others). ${ }^{16}$ As it turned out, the choice of this error probability was approximately validated ex post by the actual error probabilities observed in the respective treatments (see footnote 26).

The second error treatment, $P \beta+D-N$, is similar to $P f+D-N$ except that, based on the concept of quantal response equilibrium of McKelvey and Palfrey (1995, 1998), the error probabilities were calculated separately for each history of decisions, which implied that error probabilities were higher for more extreme prices. These error probabilities were also calculated based on data from treatment $P-N+$ AS (see Web Appendix B for details). As in treatment $P f+D-N$, it turned out that the assumed error rate was not significantly different from the actually observed one.

In treatments $P-N_{\text {error }}$, it is rational to follow one's own signal if one assumes (which we shall do in the following) that subjects anticipate other subjects to make errors with the same probabilities that the market maker assumes when setting prices.

Finally, treatments without prices are denoted by BHW. The no-price treatment, in which all signals of predecessors were observable, is denoted by BHW + AS.

In the price treatments, cascades should never happen, regardless of the probability parameters of the model. In the no-price treatments, the likelihood of cascades crucially depends on the a priori probability of the true state and the precision of the private signals. We have therefore looked at a number of different probability combinations shown in Table 2. For each probability combination, the last two columns in Table 2 give the minimum (maximum) net

\footnotetext{
${ }^{16}$ Note that the market maker would arrive at the same prices if, alternatively, he would assume that the decisions of a certain fixed proportion of subjects are uninformative (i.e., that there are noise traders), while the remaining subjects always follow their own signal. However, at least in our data it seems to be the case that the first interpretation is more appropriate (see Section III F for details).
} 
TABLE 2-PRoBABILITIES

\begin{tabular}{lccc}
\hline $\begin{array}{l}\text { A priori } \\
\text { probability }\end{array}$ & $\begin{array}{c}\text { Signal precision } \\
P(A)\end{array}$ & & \\
& $P(a \mid A)$ & $\Delta A$-cascade & $\Delta B$-cascade \\
\hline 55 & 60 & 1 & -2 \\
51 & 55 & 1 & -2 \\
55 & 80 & 1 & -2 \\
$50^{\#}$ & 66 & 2 & -2 \\
$60^{\#}$ & 60 & 1 & -3 \\
60 & 51 & -9 & -12 \\
60 & 55 & -1 & -4
\end{tabular}

Note: In cases marked by \#, we employ the tie-breaking rule that subjects follow their own signal when indifferent.

number of imputed signals necessary for the start of an $A$ cascade ( $B$ cascade), respectively.

Payoffs in "Lotto-Euros" were calculated as follows. If a subject chose the correct investment, he received 10 Lotto-Euros. This was the final payoff for this task in the BHW treatments. In the price treatments, subjects received additionally an endowment of 11 for each task to avoid losses because they had to pay the market price for their investment (which could vary between 0 and 10). Thus, the payoff from each task was $11-$ market price +10 (if successful).

\section{B. Recruiting and Payment}

The experiment was announced in several ads in the science section of the largest German weekly newspaper Die Zeit, two popular science magazines, and two national student magazines. Posters were distributed at most science faculties at German universities. Finally, e-mails were sent to Ph.D. students and postdoctoral students in science and economics departments at 35 universities in Germany. The Web site www.a-oder-b.de was linked to the Laboratory for Experimental Research in Economics at the University of Bonn and to the sponsor McKinsey \& Company to demonstrate that the experiment had a proper scientific background and that the promised financial rewards were credible.

Payoffs in the experiment, denoted in LottoEuros, were calculated as described in the previous subsection. Each Lotto-Euro was a ticket in a lottery to win one of our main prizes. In total, there were 11 prizes of 1,000 Euros each and eight prizes of 100 Euros. The odds in those lotteries were fixed in advance and known to subjects. ${ }^{17}$ Each subject, when logging in on our Web site, was told explicitly the odds per lottery ticket for winning one of our main prizes. Thus, maximizing the probability of winning one of the prizes was equivalent to maximizing the number of lottery tickets. All winners were notified by mail, and their prize money was paid through bank transfers.

In Phase I of the experiment, 1,409 subjects played with high-powered incentives where each of 40,000 lottery tickets had an equal chance of winning one of five prizes of 1,000 Euros. Since subjects played on average for 15 minutes, they were making an expected hourly "wage" of 14.19 Euros, which is comparable to a very good student job and to pay in laboratory experiments. In Phase II, each of 90,000 lottery tickets had an equal chance of winning one of another five prizes of 1,000 Euros. Finally, in Phase III, 1,162 subjects competed for the remaining 1,000 Euros. Only in this Phase III of the experiment, where almost no monetary incentives were provided, did subjects not know how many lottery tickets were issued in the respective phase. This payment scheme was due to the fact that an unexpectedly large number of subjects participated in our experiment. But it also gave us the chance to test the role of incentives in such a setting.

Phase IV consists of experiments added in January of 2004, where the number of lottery tickets issued was again fixed and known to the subjects. In this phase, 320 subjects competed for eight prizes of 100 Euros each, which amounted to an expected hourly "wage" of about 10 Euros. Subjects in this phase played only treatment groups $P-N+$ AS and $P-$ $N_{\text {error }}$, and treatments $P t+D$ and $P t+D-N$.

Additionally, there was a control group of 267 consultants from McKinsey \& Company

\footnotetext{
${ }^{17}$ This was achieved by allocating a given set of prizes to a fixed number of lottery tickets, some of which had the potential of going undistributed. No prize would have been paid when one of the few undistributed tickets had won (but this did not happen). Note that in the instructions (see Web Appendix A), it was not made explicit that, in principle, an undistributed ticket might win. This might have led (some) subjects to believe that only distributed tickets could be winners. Even if such ambiguity arose, however, its effect on incentives is likely to be mild. For example, in Phase I of the experiment, where high-powered incentives were provided, only 0.3 percent of tickets were not distributed. We thank a referee for pointing out this issue.
} 
who participated in the experiment on the same Web site a few weeks before the start of the main experiment in 2002. The subjects of the control experiment were recruited by an internal e-mail to all German consultants of McKinsey. Subjects knew that all other subjects were also consultants. About a third of those contacted participated. These subjects had the chance to win eight vouchers for a nice dinner for two in a restaurant, each worth 150 Euros.

\section{Subject Pool and Implementation}

In total, 6,419 subjects finished our experiment, of which 6,152 participated in the main experiment and 267 in the control experiment with consultants. ${ }^{18}$ Of all subjects, 13.3 percent had a Ph.D. degree and 30.2 percent were Ph.D. students. All but 6.4 percent of the subjects had either finished a first university degree or were currently enrolled at a university. Average age was 28.3, and 28.1 percent of subjects were female. Considering the number of $\mathrm{Ph} . \mathrm{D}$. students and persons with $\mathrm{Ph} . \mathrm{D}$. degrees, we believe we succeeded in recruiting a fairly bright subject pool. Furthermore, in contrast to most experiments in economics, our subjects came from a broad range of fields (about 50 percent were from natural sciences or engineering; others included business, economics, liberal arts, and law).

When arriving on our Web site, subjects read a screen that introduced the general problem and the rules of the game. Subsequently, subjects were asked for some personal information, like name, mailing address, e-mail, field of study, age, etc. Subjects were allowed to play only if all information requested was actually provided. This was also a measure to prevent subjects from playing twice: in order to win in the lottery, one had to give a correct mailing address, and the program ensured that the same name-postal code combination as well as the same e-mail address could play only once. We also used cookies to prevent using the same computer twice. ${ }^{19}$

\footnotetext{
18 There were 835 individuals who logged on but did not finish the experiment. Their decisions were not included in the history $H_{t}$ since they did not face monetary incentives (payment was conditional on finishing all three stages of the experiment).

${ }^{19}$ It will never be possible to completely prevent clever people from playing more than once. We are confident,
}

After entering the personal information, subjects were randomly placed in a currently active group, ${ }^{20}$ and had to make their first decision. Afterward, they were randomly placed in another active group for the second task, and then in a third group for the final task. No feedback about results was given until the subject had completed all three tasks. Even then they were told only how many Lotto-Euros they had won. Usually the tasks for each subject came from different treatments (except in Phase IV). Finally, we asked subjects for voluntary feedback as to how they formed their decisions, and 721 subjects sent response e-mails.

\section{Results}

For the evaluation of the results, we consider the following three measures. (a) The variable ruck is meant to capture how well theory explains the data. In all treatments (except $P-$ $N+$ AS and $P-N_{\text {error }}$ ) average ruck is defined as the fraction of decisions that were rational under the assumption of common knowledge of rationality of predecessors. ${ }^{21}$ (b) The fraction of cases in which subjects followed their own signal is denoted by own. (c) Finally, the actual market price $p_{t}$ is compared to the full information price $p_{t}^{*}$, which would have resulted if the market maker could have directly observed the signals. $^{22}$

Before we present the results, it might be useful to collect the theoretical hypotheses for

however, that not many such attempts were successful, and given the size of the subject pool, those few probably do not matter much. It turned out that less than 5 percent of the participants entered an invalid e-mail address (including unintentional typos), and these subjects did not behave significantly differently (see Section III G).

${ }^{20}$ A group was active when it was neither full nor closed (i.e., when another subject was active in this group). We also ensured that subjects who logged on at about the same time were allocated to different treatments to prevent "observational learning" in case two subjects sat next to each other in a computer pool.

${ }^{21}$ In the full information treatments $P-N+\mathrm{AS}$, common knowledge of rationality of predecessors is not required. In treatments $P-N_{\text {error }}$, average ruck is defined as the fraction of decisions that were rational given the assumption that the market maker's model of the behavior of one's predecessors was correct.

${ }^{22}$ In all but $P-N_{\text {error }}$, the full information price is equivalent to the theoretical price that would have resulted if all subjects had behaved according to ruck. 
Table 3-Number of Groups per Treatment and Probability Combination

\begin{tabular}{|c|c|c|c|c|c|c|c|c|}
\hline \multirow[b]{2}{*}{ Treatment } & \multicolumn{7}{|c|}{ Probability combination } & \multirow[b]{2}{*}{ Total } \\
\hline & $50-66$ & $51-55$ & $55-60$ & $55-80$ & $60-51$ & $60-55$ & $60-60$ & \\
\hline$P+D$ & 12 & 6 & $26+15^{c}$ & 8 & - & 6 & 4 & 77 \\
\hline$P-D$ & 11 & 6 & $20+9^{c}$ & 1 & - & - & 3 & 50 \\
\hline$P e+D$ & 12 & 6 & 12 & 6 & - & 6 & - & 42 \\
\hline$P t+D$ & - & - & 9 & - & - & - & - & 9 \\
\hline$P+D-N$ & 10 & 6 & 18 & - & - & - & - & 40 \\
\hline$P t+D-N$ & - & - & 9 & - & - & - & - & 9 \\
\hline$P-D-N$ & 17 & 6 & 18 & - & - & - & - & 41 \\
\hline$P+\mathrm{AS}+D-N$ & - & - & 6 & - & - & - & - & 6 \\
\hline$P+\mathrm{AS}-D-N$ & - & - & 6 & - & - & - & - & 6 \\
\hline$P f+D-N$ & - & - & 9 & - & - & - & - & 9 \\
\hline$P \beta+D-N$ & - & - & 9 & - & - & - & - & 9 \\
\hline BHW & 12 & 17 & $65+15^{c}$ & 8 & 12 & 6 & 15 & 150 \\
\hline $\mathrm{BHW}+\mathrm{AS}$ & 12 & 18 & $70+9^{c}$ & 2 & 12 & - & 12 & 135 \\
\hline Total & 92 & 65 & $277+48^{c}$ & 25 & 24 & 18 & 34 & 583 \\
\hline
\end{tabular}

Notes: As a convention, the first number in $x-y$ is the prior and the second the signal precision used in the experiment. The symbol ${ }^{c}$ denotes groups in the control experiment with consultants.

our various treatments (see the discussions in Sections I and II A above). (a) In all price treatments, subjects should follow their own signal $(r u c k=o w n=1)$. (b) There should not be any difference between any of the treatments in $P$ and $P-N$, regardless of whether prior decisions were observable or not $(+D$ or $-D)$ or whether the option $N$ was available or not. (c) In treatment groups $P$ and $P-N$, actual prices $p_{t}$ should match full information prices $p_{t}^{*}$ (d) The no-trade option $(N)$ should never be used. (e) In treatment BHW, subjects should follow the cascade behavior described in the last two columns of Table 2 if they believe that their predecessors are rational (ruck = 1). (f) In treatment BHW + AS, subjects should follow the cascade behavior of Table 2 regardless of what they believe about others $($ ruck $=1)$. (g) Different prior probabilities and signal precisions should not alter average ruck.

\section{A. Preliminary Data Analysis}

Table 3 gives the number of groups in our experiment separately for each combination of treatments and probabilities. As stated above, the group size was usually 20 (it was ten for treatment $\mathrm{BHW}+\mathrm{AS}$ and the control experiment with consultants).

Since reporting results for each variation would be tedious, we checked first which variants of our treatments could be grouped together and pooled. We did this by comparing treatments with respect to the variables ruck and own, both by nonparametric MWU tests and regressions, taking each group as one observation. The following summarizes the results of those tests:

Incentives. The phase of the experiment (recall that incentives were different in Phases I through IV) had no significant effect. This implies that-at least in this experiment-incentives seem to matter little as compared to the intrinsic motivation of subjects to perform well. ${ }^{23}$

Stage. The stage of the task (whether a task was the first, second, or third a subject performed in) did not matter. This shows that learning effects do not play a significant role. This is in line with our expectations, given that subjects did not receive any feedback until the end of the game.

\footnotetext{
${ }^{23}$ Colin Camerer and Robin Hogarth (1999) provide a survey of studies that look at the effects of monetary incentives.
} 
TABLE 4-AVERAGE ruck

\begin{tabular}{lccccccc}
\hline \hline $\begin{array}{l}\text { Probability } \\
\text { combination }\end{array}$ & $P$ & $P-N$ & $P-N+\mathrm{AS}$ & $P f+D-N$ & $P \beta+D-N$ & $\mathrm{BHW}$ & $\mathrm{BHW}+\mathrm{AS}$ \\
\hline $55-60$ & 0.54 & 0.65 & 0.65 & 0.68 & 0.70 & 0.66 & 0.72 \\
& $(0.12)$ & $(0.11)$ & $(0.15)$ & $(0.10)$ & $(0.07)$ & $(0.11)$ & $(0.14)$ \\
$50-66$ & 0.59 & 0.68 & - & - & - & 0.78 & 0.76 \\
& $(0.11)$ & $(0.09)$ & - & - & - & $(0.09)$ & $(0.12)$ \\
\hline
\end{tabular}

Note: Standard deviations in parentheses.

Instructions. Presenting the pricing rule through a table $(t)$ does not change the results, as there are no significant differences between $P+D$ and $P t+D$, or between $P+D-N$ and $P t+D-N$, respectively. Also, a more explicit formulation for the price formation process $(e)$ was irrelevant, which, given that a large fraction of the subject pool has a mathematical background, is reassuring and indicates that subjects understood how prices were formed. The two versions of the instructions (see footnote 13) made no significant difference.

Observability of decisions. The observability of decisions of predecessors did not matter, which implies that subjects understood how their predecessors' decisions are reflected in the price history.

With the exception of $P-N_{\text {error }}$, we will, therefore, report only results on the treatment group level (see Table 1) because treatments within these treatment groups did not significantly differ from each other. ${ }^{24}$ In the following, we will present the results from the main experiment. Results from the control experiment with consultants are reported in Section III H.

\section{B. Summary Statistics}

In this subsection, we present summary statistics on the main variables of interest, ruck and own. Recall that theory predicts ruck $=1$ for all treatments. Table 4 shows average ruck for seven treatment groups and the probability combinations 55-60 and 50-66. ${ }^{25}$

\footnotetext{
${ }^{24}$ Differences across treatment groups are discussed below.

${ }^{25}$ Since in the BHW treatments the observed ruck varies with different probability combinations, we compare treatments only for our main probability combinations 50-66 and 55-60. In Web Appendix C, we display the average values of ruck and own across all probability combinations.
}

In the $P-N$ treatments, average ruck is 65 percent and 68 percent, respectively, i.e., roughly two-thirds of subjects in these treatments acted in line with theory. In the $P-N+$ AS treatments and the two error treatments $P f+$ $D-N$ and $P \beta+D-N$, average ruck is between 65 percent and 70 percent. $^{26}$ None of the treatments without the $N$ option $(-N)$ is significantly different at any conventional level according to pairwise nonparametric MWUtests. In the $P$ treatments ruck is substantially and significantly lower, probably because an additional mistake can be made, namely not to trade. ${ }^{27}$ In fact, $N$ was chosen on average 19 percent of the time in the $P$ treatments, which was never ruck. ${ }^{28}$ Among subjects who did buy $A$ or $B$ in treatment $P$, average ruck was similar to the $-N$ treatments, namely 66 percent $(71$ percent) in probability combination 55-60 (5066). Average ruck in BHW reaches 66 percent and 78 percent, respectively. Even in BHW +

\footnotetext{
${ }^{26}$ Binomial tests do not allow to reject the hypothesis that for any observed price the actual probability with which subjects followed their signal in $P f+D-N$ is equal to the ex ante assumed probability of 0.6542 (pooled over all prices in treatment $P f+D-N$, subjects followed their signal in 68 percent of cases (see Table 4)). In the price calculation in treatment $P \beta+D-N$, we used an error rate $\beta=0.5552$ (derived from treatment $P-N+\mathrm{AS}$ ). Estimating such an error rate ex post from the data of $P \beta+D-$ $N$ (see Section III F and in particular footnote 44) yields 0.471 (standard deviation 0.09 ), which is not significantly different from 0.5552 .

${ }^{27}$ Risk aversion cannot really account for this behavior, since we employed a binary lottery procedure which, at least theoretically, should induce risk neutrality (see Alvin Roth and Michael Malouf, 1979, or Joyce Berg et al., 1986).

28 These findings are roughly in line with Cipriani and Guarino (2005). In their flexible price treatment (with probability combination $50-70)$ they report that 65 percent $(22$ percent) of subjects acted rationally (did not trade), which is comparable to our treatments $P$ 50-66 where the respective numbers are 59 percent and 24 percent.
} 
Table 5-Average ruck in Treatment $P$ ACRoss PROBABILITY COMBINATIONS

\begin{tabular}{lccccc}
\hline \hline \multicolumn{5}{c}{ Probability combination } \\
\hline $55-60$ & $50-66$ & $51-55$ & $55-80$ & $60-55$ & $60-60$ \\
\hline 0.54 & 0.59 & 0.56 & 0.53 & 0.51 & 0.60 \\
$(0.12)$ & $(0.11)$ & $(0.13)$ & $(0.11)$ & $(0.13)$ & $(0.10)$ \\
\hline
\end{tabular}

Note: Standard deviations in parentheses.

AS, where there is no need to worry about the rationality of others, ruck reaches only 72 percent and 76 percent, respectively.

A curious pattern appears with respect to the percentage of subjects who followed their own signals (own). In the 55-60 and 50-66 BHW sessions, 75 percent of subjects (see Web Appendix C) follow their own signal (often in contrast to what they should do). ${ }^{29}$ On the other hand, in the price treatments, only between 54 percent and 70 percent of subjects follow their own signal, when following the own signal is always ruck.

Finally, we can take a more detailed look how ruck varies for different probability combinations. Table 5 shows ruck levels for treatment $P$. Taking our main treatment $55-60$ as base, only 50-66 shows a significant difference at the 5-percent level, according to MWU tests. ${ }^{30}$ Hence, results from the price treatments seem to be fairly robust across probability combinations.

\section{Actual versus Full Information Prices}

The key question with respect to the efficient market hypothesis is whether prices accurately reflect the information in the market. Clearly, informational efficiency presupposes that individual traders act rationally on their information and, as we have seen in the last subsections, this is not always the case in our experiment. Consequently, in this subsection, we look at how strongly prices are distorted relative to the full information benchmark. We define the full information price $p_{t}^{*}$ as the price that would have

${ }^{29}$ In equilibrium (when all subjects are ruck) own should be about 60 percent (see, again, Web Appendix C).

${ }^{30}$ Differences across probability combinations look similar in treatment $P-N$ but not all combinations were played for this treatment group.
Table 6-Ratios of Full Information Final Prices to Actual Final Prices

\begin{tabular}{lcc}
\hline \hline Treatment & If $A$ is successful & If $B$ is successful \\
\hline$P$ & 1.38 & 0.46 \\
$P-N$ & 1.42 & 0.57 \\
$P \beta+D-N$ & 0.98 & 0.40 \\
$P f+D-N$ & 1.11 & 0.51 \\
\hline
\end{tabular}

Note: Pooled over all probability combinations.

resulted if the market maker could have observed the private signals.

While in the long run the full information price will converge to the true value of the asset, this is not necessarily the case in the short or medium run. To judge how well actual prices incorporate available information, we first look at convergence of final prices (i.e., prices after the decision of the last player) to full information final prices. Our data show that final prices are rarely close to the final full information price. In $P-N$, the final price deviates by more than 20 percent from the final full information price in 75 percent of groups (pooled over all probability combinations). The option of not trading in treatment $P$ makes things worse, since now 82 percent of end prices deviate by more than 20 percent from final full information prices. In the error treatments $P f+D-N$ and $P \beta+D-N$, convergence is even rarer, as in both of these treatments 89 percent of final prices deviate by more than 20 percent from final full information prices.

Table 6 depicts the ratio of the final full information price of asset $A$ to the actual final price of asset $A,\left(p_{T+1}^{*} / p_{T+1}\right)$, separately for states where asset $A$ is successful and where asset $B$ is successful. An important observation is that full information prices tend to be more extreme than actual prices. In other words, actual prices undershoot: when state $A(B)$ is true, the actual final price of $A$ is on average too low (high).

In a next step, in Figure 1 we consider the empirical distribution of actual prices (upper panels) and full information prices (lower panels) in treatments $P-N$ and $P-N_{\text {error }}$ pooled over all periods and probability combination $55-60 .{ }^{31}$ In general, full information prices are

\footnotetext{
${ }^{31}$ Actual (full information) prices include the decision (signal) of the current subject. The figures for treatment $P$ and for other probability combinations look similar. Treatment
} 

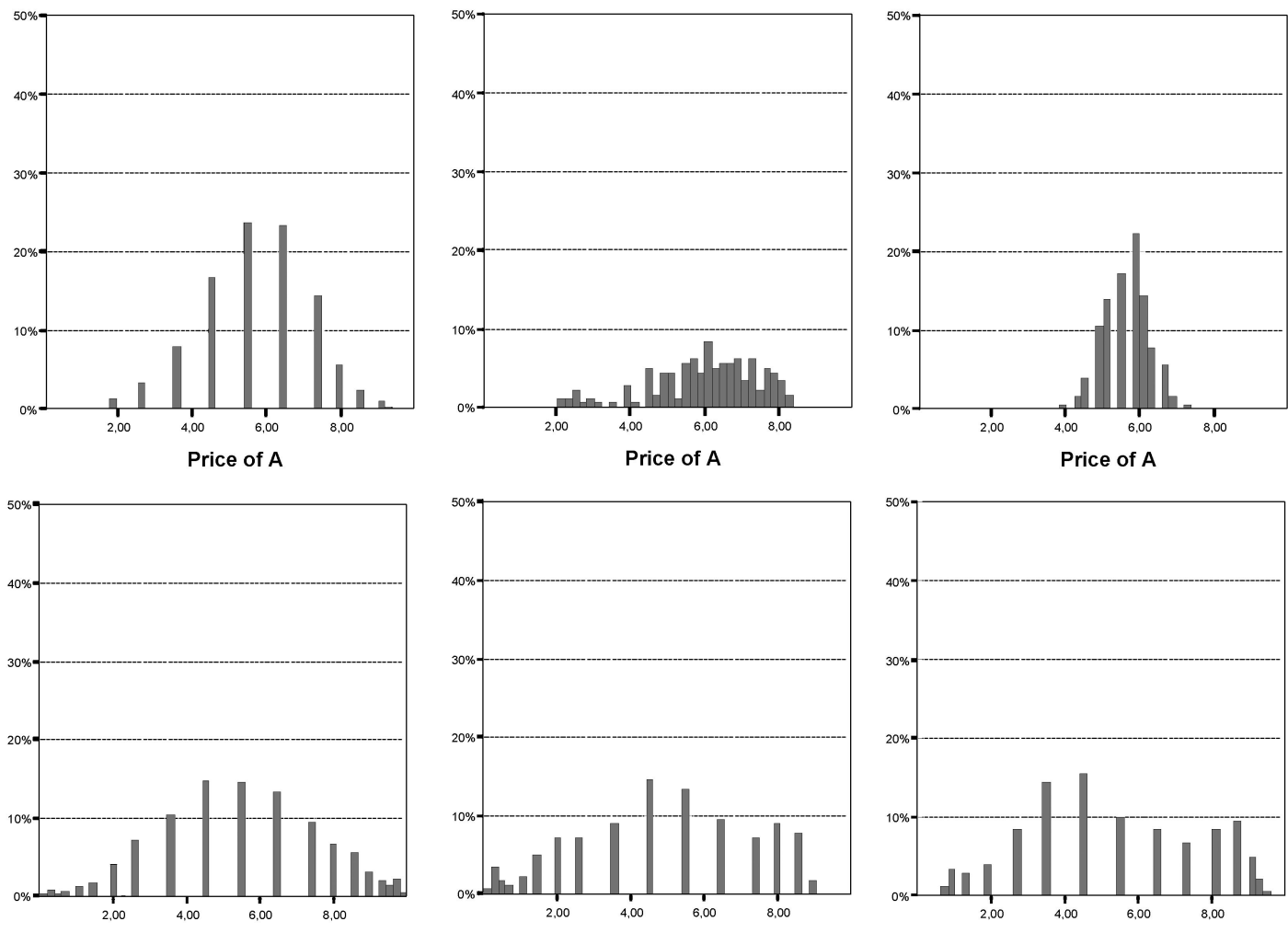

Full information price of $A$
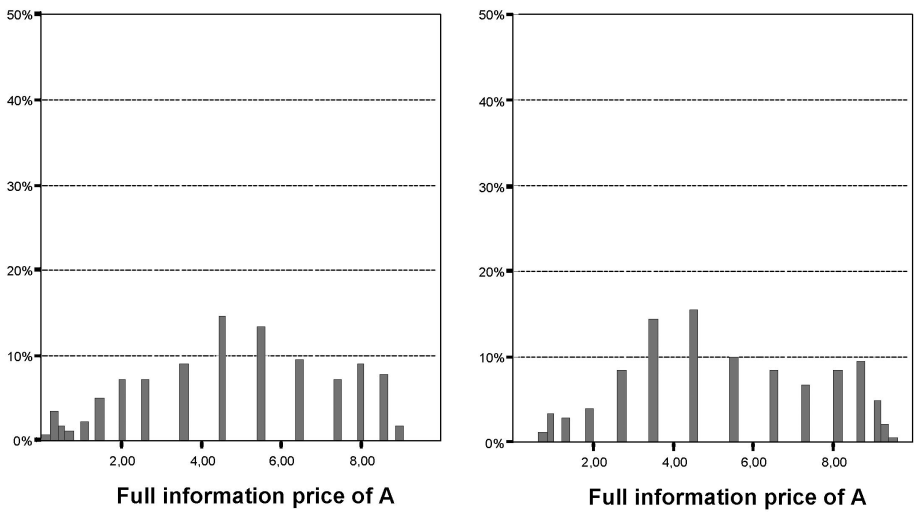

Figure 1. Distribution of Actual Prices and Full Information Prices over all Periods

Note: Observations from treatments $P-N, P \beta+D-N$, and $P f+D-N$, given probability combination 55-60.

concentrated around the a priori price. The distribution of actual prices matches this feature well but the distributions are even more concentrated. Extreme prices are rarely observed. It is interesting to see that even though a high fraction of subjects behaves seemingly irrationally, the volatility in the actual prices is less than the volatility in the full information prices.

That deviations between the full information and actual price can be severe is illustrated in the left panel of Figure 2, which shows the average deviation $\left(p_{t}^{*}-p_{t}\right)$ across full information prices $p_{t}^{*}$ (not only final ones). The graph clearly indicates that actual prices undershoot and are less extreme than the theoretical prediction.

Finally, over time deviations become more severe. The right panel of Figure 2 shows that the average relative distance between full information price and actual price increases. ${ }^{32}$ Note that by construction of the price mechanism, deviations in the early rounds must be small. More interestingly, there is no inverted U-shape form which would indicate convergence over time. In the next subsection we shall consider possible explanations for those deviations.

\footnotetext{
32 The observed divergence over time may explain the higher levels of convergence reported by Cipriani and Guarino (2005), who consider groups of 12 subjects.
} 

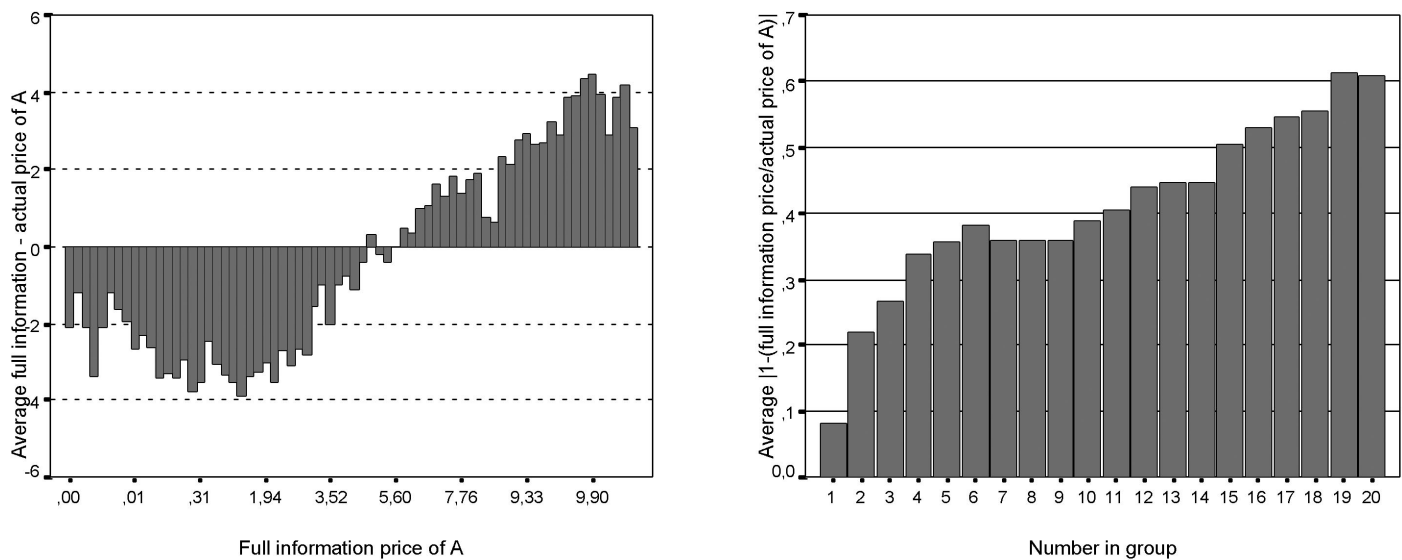

Figure 2. Average Price Deviation, Given a Full information Price (Left Panel), and Average Relative Distance between Full Information Price and Actual Price of $A$, Given the Number in the Group (Right Panel)

Notes: The average price deviation is calculated as the difference between the full information price and the actual price of $A$. Observations from treatment $P-N$ pooled over all probability combinations.

\section{Possible Explanations: Imitation and Contrarians}

An obvious candidate explanation for observed deviations from the full information prices is herd behavior. As explained in Section $\mathrm{I} \mathrm{B}$, rational herding is impossible in our framework. However, if subjects indeed behave like "lemmings," they would imitate prior decisions and thus produce herd-like behavior. We find, however, that imitation plays no significant role.

The first evidence against imitation in treatments with flexible market prices stems from inspecting Figures 1 and 2, which show that, on average, actual prices are less extreme than full information prices. Yet, imitation would predict the opposite. If, for example, an early investor in asset $A$ induced later investors to buy $A$ even though they got a $b$ signal, this would quickly drive the actual price above the full information one. Likewise, an early investor in $B$ should drive down the price of $A$ more quickly than the full information price, since imitation would yield more buyers of $B$ than justified by private information.

To check more rigorously for imitation on the individual level, we analyze whether subjects' choices are influenced by the decisions of their direct predecessors. If a subject is more likely to choose $A$ after (say) three subjects immediately before him also chose $A$, we would take that as an indication for imitative behavior. Let pred measure the number of direct predecessors who chose an identical action. The variable is positive if this action was $A$ and negative if the action was $B .{ }^{33}$ In Table 7 , we report results from logit regressions for all $-N$ treatments in order to test whether the $0-1$ variable "choice of $A$ " is influenced by pred. ${ }^{34}$ Besides pred, the following explanatory variables were used: (i) Price of $A$; (ii) dhint, which is a dummy variable that was 1 if the private information of the subjects in question was $a$ and 0 otherwise; and (iii) a constant and, in case of $P-N$, dummies for the various probability combinations.

The dummy for private information dhint has the expected signs and is significant. The coefficient for the price of $A$ is negative and significant in all cases (this is discussed in more detail below). However, in all but one case, the coefficients for the imitation variable pred are not

\footnotetext{
${ }^{33}$ Alternatively, we included dummies if the number of $A$ or $B$ predecessors is greater than a certain threshold. This change was inconsequential.

${ }^{34}$ In treatments $P$ we ran ordered logits with the endogenous variable taking the values 1 (choice of $A$ ), 0 (no trade), and -1 (choice of $B$ ), and obtained qualitatively the same results as in $P-N$. Since, from a theoretical point of view, $N$ should never be chosen, it is not perfectly clear whether $A, B$, and $N$ can indeed be ordered. Hence, we also ran multinomial logits which also qualitatively yielded the same results. The independence of irrelevant alternatives underlying the multinomial model is fulfilled.
} 
Table 7-Logit Analysis: Choice of $A$ in Price Treatments

\begin{tabular}{lcccc}
\hline \hline & $P-N$ & $P f+D-N$ & $P \beta+D-N$ & $P-N+\mathrm{AS}$ \\
\hline Price of $A$ & $-0.371^{* *}$ & $-0.837 * *$ & $-0.330^{*}$ & $-0.377^{* *}$ \\
& $(0.040)$ & $(0.323)$ & $(0.137)$ & $(0.068)$ \\
dhint & $1.569 * *$ & $1.540^{* *}$ & $1.802^{* *}$ & $1.720^{* *}$ \\
& $(0.112)$ & $(0.334)$ & $(0.345)$ & $(0.321)$ \\
pred & -0.016 & 0.068 & $0.132^{*}$ & -0.065 \\
& $(0.033)$ & $(0.086)$ & $(0.064)$ & $(0.068)$ \\
\hline Observations & 1659 & 180 & 180 & 240 \\
-2 Log-Likelihood & 1985.31 & 216.60 & 210.43 & 269.77 \\
$R^{2}$ (Nagelkerkes) & 0.230 & 0.221 & 0.256 & 0.295 \\
\hline
\end{tabular}

Notes: In the regressions, all probability combinations are used. All regressions include a constant and, in case of $P-N$, dummies for probability combinations. Standard deviations are given in parentheses. ** Significantly different from 0 at the 1 -percent level. * Significantly different from 0 at the 5-percent level.

significantly different from zero. In $P \beta+D-N$, the pred variable is significant at the 5-percent level $(p$-value $=0.038)$. It turns out, however, that in this treatment pred is not significant if one excludes from the regression the 7 (out of 180) cases where pred is larger or equal to 7. That is, only after a relatively long sequence of identical decisions do subjects seem to imitate the choice of their predecessors. It seems that in the presence of a flexible market price, imitation cannot really explain our data. ${ }^{35}$

If imitation is not the right story to explain the deviations between the full information and actual price, what is? We suggest a story based on contrarian behavior, which can be justified by a regression to the mean argument. As explained above, we say that a subject is a contrarian if he trades against his signal and against the market, or, equivalently, if he receives an $a$ (b) signal at a price for $A$ which is strictly above (below) the a priori price (i.e., ten times the a priori probability for $A$ ) and deviates from his signal to buy $B(A)$ instead. Such contrarian behavior can be (ex post) rational only if the trader is convinced that prior traders irrationally drove the price to an extreme.

Figure 3 gives evidence in favor of contrarian behavior. It shows average frequencies of ruck for treatment $P-N$ and probabilities 55-60 given that the subject has received an $a$-signal. The higher the price, the more likely subjects

\footnotetext{
${ }^{35}$ A multinomial logit regression of treatment $P$ confirms that there is also no imitation with respect to the no-trade decision $N$.
}

are to trade against their signals and the lower ruck. ${ }^{36}$ Average ruck drops from around 85 percent at low prices to around 50 percent at high prices.

These findings are confirmed in our regression analysis (see again Table 7). High prices for $A$ significantly lower the probability of choosing asset $A$ in all regressions.

\section{E. Does It Pay to Be a Contrarian?}

While Section III D provides evidence for contrarian behavior, the question arises whether it is a good idea to be a contrarian (at least in the treatments other than our benchmark treatments $P-N+\mathrm{AS}$, where the answer is always no). There is a paradox here since contrarian behavior is profitable if and only if prices are overvalued, but if there are many contrarians, prices are not overvalued. The current and the next subsection will address this issue.

First, we turn to the question whether contrarian behavior is actually profitable. A first aggregate look at the data suggests that this is not the case. Table 8 lists average profits (excluding the fixed payment of 11 in the price treatments) of subjects, depending on whether subjects were ruck or not. In all cases, ruck yields higher average profits. The last column of Table 8 contains Pearson correlation coefficients between ruck and profits. All correlation

\footnotetext{
${ }^{36}$ Other treatments and probability combinations yield qualitatively similar figures (for both possible signal realizations).
} 


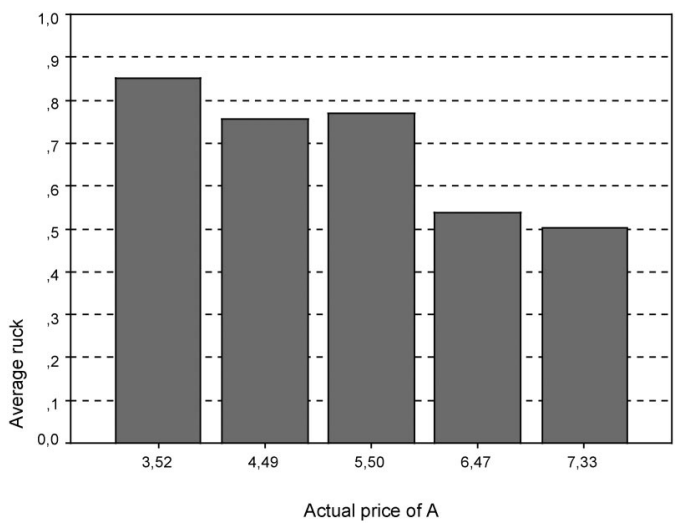

Figure 3. Average ruck Given an a Signal across ACtual Prices of $A$

Notes: Observations from treatment $P-N$, given probability combination 55-60. More extreme prices than those shown are omitted due to low numbers of observations.

coefficients are positive and significantly different from zero at the 1-percent (10-percent) level in treatments $P$ and $P-N(P f+D-N){ }^{37}$

It seems plausible that contrarian behavior might be sensible if actual prices are extreme. To check this, we compare the profit of a contrarian with the counterfactual profit he would have received had he played according to theory. Since $p_{t}=(10-$ price of $B)$, it is straightforward to show that the counterfactual payoff is always ( -1$)$ times the actual profit. If we pool over all probabilities and consider prices that deviate by more than two from the a priori price $p_{0}$, we get the results presented in Table 9. While in treatment $P$, contrarians always do worse than their counterfactual rational subjects, in treatment $P-N$, being a contrarian was profitable for prices that are more than two away from $p_{0} \cdot{ }^{38}$ In $P-N$ for extreme prices, a contrarian is actually more successful than a counterfactual, ruck subject would be. ${ }^{39}$

37 This also holds in BHW and BHW + AS. On average, ruck players earned 6.1 in $\mathrm{BHW}$ and $\mathrm{BHW}+\mathrm{AS}$, whereas others earned 4.4 in BHW and 3.4 in BHW + AS.

${ }^{38}$ In $P-N_{\text {error }}$, there were hardly any observations of potential contrarians for extreme prices, which is why these treatments are not shown in Table 9. For intermediate prices, contrarians earn negative profits in these treatments.

${ }^{39}$ One possible explanation for the difference between $P$ and $P-N$ is that prices in $P-N$ have a higher variance (3.1 rather than 2.6 in $P$ pooled over all probability combi-
TABle 8-Average Profits AND ruck

\begin{tabular}{lccc}
\hline \hline & \multicolumn{2}{c}{$\begin{array}{c}\text { Average profits of } \\
\text { subjects classified as }\end{array}$} & \\
\cline { 2 - 3 } Treatment & ruck $=1$ & ruck $=0$ & $\begin{array}{c}\text { Correlation } \\
\text { coefficients }\end{array}$ \\
\hline$P$ & 1.3 & -0.5 & $0.21^{* *}$ \\
$P-N$ & 1.0 & -0.4 & $0.13^{* *}$ \\
$P \beta+D-N$ & 0.1 & -1.1 & 0.10 \\
$P f+D-N$ & 0.6 & -0.8 & $0.13^{*}$ \\
\hline
\end{tabular}

Notes: Pooled over all probability combinations. Profits exclude fixed payments. ** Significantly different from 0 at the 1-percent level. * Significantly different from 0 at the 10-percent level.

Table 9-Contrarians' Average Profits in Different PRICE REGIONS

\begin{tabular}{lccc}
\hline & $p_{t}-p_{0} \geq 2$ & $2 \geq p_{t}-p_{0} \geq-2$ & $p_{t}-p_{0} \leq-2$ \\
\hline$P$ & -0.4 & -0.8 & -0.5 \\
$P-N$ & 0.9 & 0.0 & 0.9 \\
\hline
\end{tabular}

Notes: Pooled over all probability combinations. Profits exclude fixed payments. $p_{0}$ denotes the a priori price.

\section{F. An Error Model to Explain Contrarian Behavior}

When can contrarian behavior be optimal? Let us assume that some traders behave like noise traders; in particular, they choose $A$ and $B$ more or less randomly. This implies that whenever the actual price is very high or very low, it is likely that this was driven by noise traders. In other words, whenever the actual price is extreme, the full information price is likely to be less extreme. Vice versa, whenever the full information price is extreme, the actual price is likely to be less extreme, which is simply a regression to the mean argument. Given that traders anticipate the random behavior of noise traders, they should be contrarians because a low price for $A$ yields a buying opportunity, even if their private information is favoring $B .^{40}$ Given that there are some contrarians among the traders, actual prices will, on average, be less extreme than theoretical ones, just as observed in our data (see Figure 1).

nations), which could make it more attractive to be a contrarian. We thank a referee for pointing that out to us.

${ }^{40}$ This does not hold in the error treatments where the market maker, when setting the price, takes into account that not all subjects follow their signal. 


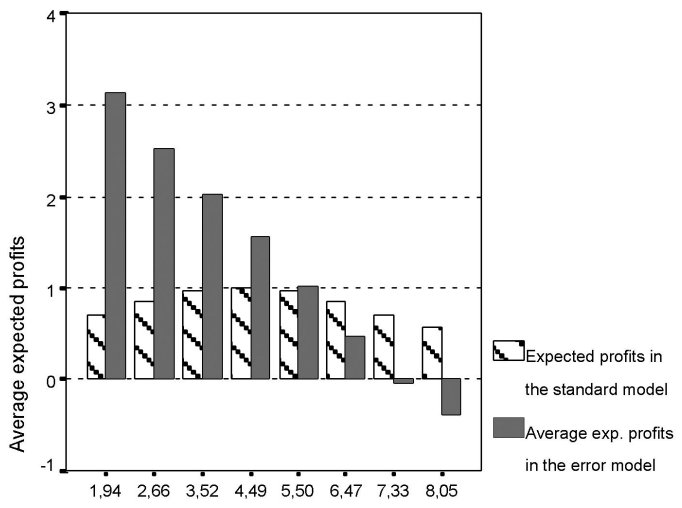

Actual price of $A$

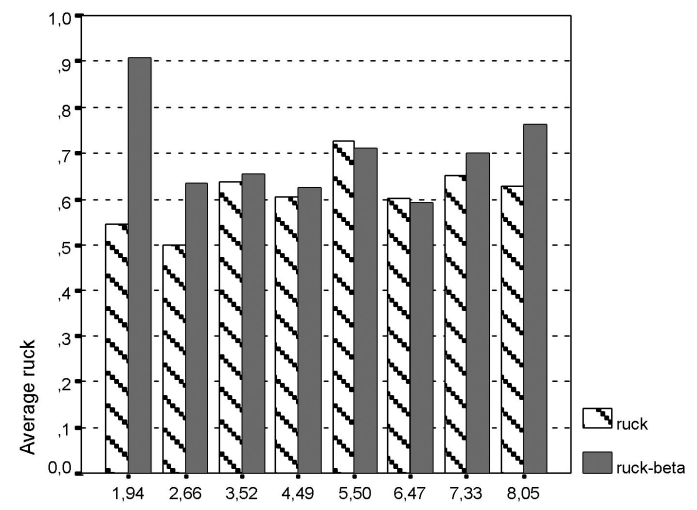

Actual price of $A$

Figure 4. Average Expected Net Profits of Buying Asset A Given an $a$ Signal (Left Panel), and Average ruck (Right Panel) in the Standard Model and in the Error Model Across Prices

Note: Observations from treatment $P-N$ given probability combination 55-60.

As discussed in the introduction, in this subsection, we explicitly incorporate the possibility that subjects could be aware of the fact that others make mistakes. The error model is based on the concept of quantal response equilibrium of McKelvey and Palfrey (1995, 1998). In particular, it is assumed that subjects choose the correct action according to a logit function that depends on the difference in payoffs between the two alternatives. ${ }^{41}$ If the difference is large, the correct action is chosen with high probability. If it is small, mistakes are more likely. Analogous to Anderson and Holt (1997), we estimate error parameters $\beta_{t}$ for treatment $P-$ $N$ recursively for each round $t=1, \ldots, 20$, taking into account that predecessors have reacted to possible earlier errors. (For details of the estimation and for all coefficient estimates, see Web Appendix D.) ${ }^{42}$ The coefficients for the $\beta_{t}$ range between 0.58 and 0.08 , and all but one of the 20 coefficients, are significant at the 5-percent level. ${ }^{43}$

\footnotetext{
${ }^{41}$ Since in treatment $P$ each subject has three possible choices, we do not estimate an error model for this treatment.

${ }^{42}$ The error model above assumes a full level of reasoning. See Kübler and Weizsäcker (2004) for an estimation with various degrees of reasoning.

${ }^{43}$ In order to make our coefficients comparable to those of Anderson and Holt (1997), one has to multiply them by approximately five to account for the larger range in payoffs in our experiment (see Web Appendix D for details). Nevertheless, our estimates are somewhat smaller.
}

As it turns out, if one pools over all probability combinations, average ruck in the error model (denoted by ruck - $\beta$ ) and ruck under the standard model are both equal to $0.67 .{ }^{44} \mathrm{We}$ believe that this is due to the fact that, in our case, errors do not change the optimal actions for most prices, even though expected profits do change. This can be seen in the left panel of Figure 4, which shows average expected profits of buying asset $A$ given an $a$ signal depending on the assumptions with respect to errors of predecessors (treatment $P-N, 55-60)$ ). In the standard model, where agents hold the belief that all agents follow their signal, it is always optimal to follow one's signal as well. Not so with the error model. The left panel of Figure 4 shows that, at low or moderate prices for asset $A$, agents should optimally follow an $a$ signal, but at high prices contrarian behavior is optimal. Given the left panel of Figure 4, it is not surprising that average ruck at moderate prices is similar under both definitions of rationality. Only at very high and very low prices, ruck

\footnotetext{
${ }^{44}$ We have analyzed two additional error models. First, in an iterative process, we estimated a constant parameter $\beta$ across all rounds: in each iteration, expected profits were calculated by using the error parameter obtained in the previous estimation, and we observed convergence of $\beta$ after approximately 20 iterations. Second, we also analyzed a simpler error model in which the error probability was assumed to be constant, i.e., history-independent. The results from both of these modified error models are qualitatively the same as those reported above.
} 
TABLE 10-FREQUENCY OF ruck WHEN PLAYING $P-N+$ AS Three TIMES

\begin{tabular}{lcccc}
\hline \hline & 0 & 1 & 2 & 3 \\
\hline $\begin{array}{l}\text { Frequency in actual data } \\
\begin{array}{l}\text { Expected if rational with } \\
\text { probability 0.6542 }\end{array}\end{array}$ & 0.063 & 0.213 & 0.425 & 0.300 \\
$\quad$ & 0.235 & 0.444 & 0.280 \\
\hline
\end{tabular}

increases in $P-N$ if one allows for the possibility of errors (see the right panel of Figure 4).

These results have implications for the discussion about "noise traders" in market microstructure models. As discussed earlier, in a model where there are only informed traders and where a market maker sets a bid-ask spread, the no-trade theorem would apply. To avoid this, most market microstructure models introduce noise traders ad hoc. ${ }^{45}$

First, our results suggest that "noise" seems to emerge automatically due to the irrationality of some of the traders. This becomes especially obvious in our $P-N+$ AS treatments where, pooled over all probability combinations, average rationality is still only 65 percent. This observation, together with the fact that even under the error model ruck does not exceed 70 percent, suggests that the problem is not so much extracting the relevant information from the decision of predecessors as it is processing it correctly. Second, our data provide support for the hypothesis that each agent decides rationally with a certain probability, as opposed to the hypothesis that some of the subjects always decide rationally while others always decide irrationally. This can be seen by considering the 80 subjects who played three times $P-N+$ $\mathrm{AS}$, which does not require assumptions with respect to the rationality of predecessors. Table 10 depicts how many of these subjects made zero, one, two, or three rational decisions. A two-sided Kolmogorov-Smirnov test reveals that this distribution is not significantly different (at any conventional level) from a distribu-

${ }^{45}$ To justify the presence of noise traders, it has been argued that (rational) noise traders act due to liquidity or hedging needs (see, e.g., Lawrence Ausubel, 1990) or due to incentives arising from optimal delegation contracts for portfolio managers (see, e.g., James Dow and Gary Gorton, 1997). Following Fischer Black (1986), there is a strand of the literature in which noise traders are seen as traders that trade on noise as if it were information or as agents who just act randomly.
TABle $11-A v e r a g e ~ r u c k$ of Subgroups IN PRICE TREATMENTS

\begin{tabular}{lcccccc}
\hline \hline Male & Female & College & $\begin{array}{c}\text { No } \\
\text { college }\end{array}$ & Ph.D. & students & All \\
\hline 0.60 & 0.60 & 0.61 & 0.55 & 0.64 & 0.61 & 0.60
\end{tabular}

Note: Data from treatment groups $P, P-N, P-N+\mathrm{AS}$, and $P-N_{\text {error }}$ pooled over all probability combinations.

tion that would result if each of these subjects had always decided rationally with probability 0.6542 , which is the average value of ruck in $P-N+$ AS.

\section{G. The Influence of Personal Characteristics}

With the large number of participants in our experiment, it is possible to investigate the behavior of a variety of subgroups. For the price treatments, Table 11 compares average ruck of male and female subjects, subjects who are current or former students ("college"), subjects who have never attended college ("no college"), subjects holding a Ph.D. degree, and current Ph.D. students. To test for differences, we ran logit regressions at the individual level to explain the rationality variable ruck by dummies for the subgroups above. Controlling for the duration of play, the age of the subject, and its position in the group, we find that neither the sex of the subject nor the college dummy is significant at conventional levels. There is, however, evidence that the 13.3 percent Ph.D.s in our subject pool have a significantly higher ruck (with a $p$-value of 0.068 ). ${ }^{46}$

As a large part of our subject pool had some university education, we asked subjects for their major field of study, as it should be interesting whether there are differences in behavior. Figure 5 depicts average ruck and profits (excluding fixed payments) in the price treatments for selected fields of study. As expected, with respect to ruck, physicists, but also economists, perform above average. Business students are slightly below average and psychologists

\footnotetext{
${ }^{46}$ Controlling for the field of studies reveals that this effect is mainly driven by Ph.D.s from the sciences, medicine, and engineering. Surprisingly, there is no significant Ph.D. effect in economics. We also included a dummy to reflect whether a subject had provided an invalid e-mail address (see Footnote 19). This dummy is not significant.
} 

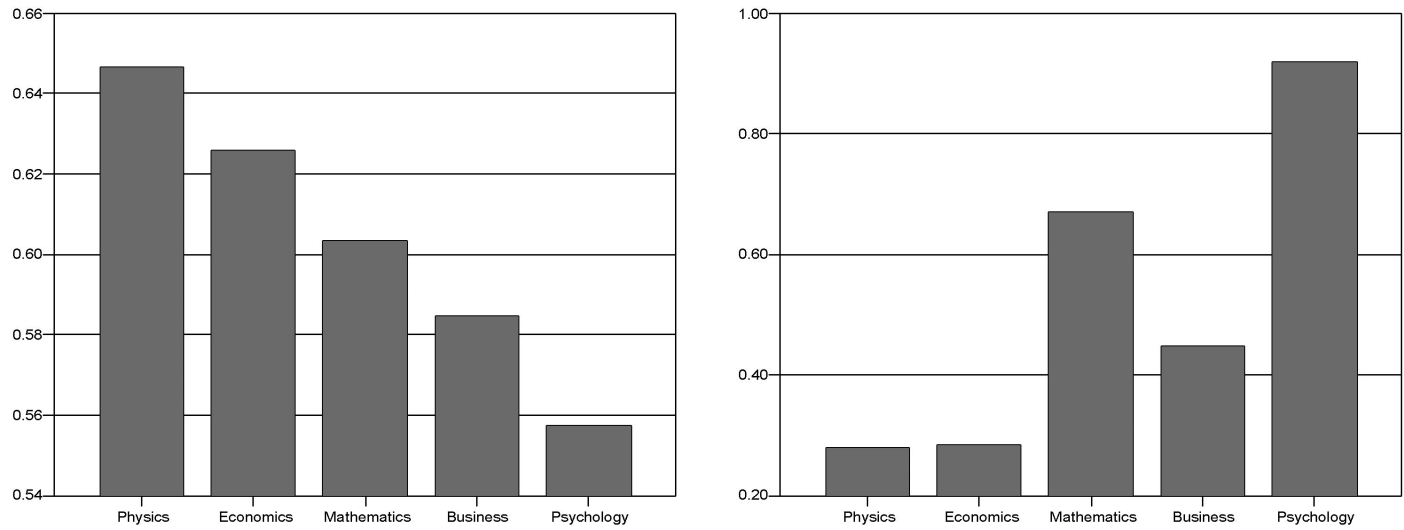

Figure 5. Average ruck (Left Panel) and Average Profits (Right Panel) for Selected Fields of Study

Notes: Observations from treatments $P, P-N, P-N+\mathrm{AS}$, and $P-N_{\text {error }}$, pooled over all probability combinations. Profits exclude fixed payments.

performed worst. If one looks at profits, however, the ranking is almost exactly reversed. Physicists and economists do much worse than psychologists. A high ruck is not necessarily a virtue if others are irrational. This suggests that sometimes an intuition for the possibly irrational behavior of others seems to be more important than being able to apply Bayes's rule. While we should not overemphasize those results (recall that profits may vary from -10 to +10 and standard deviations are rather large), we do find one interesting behavioral difference between the two extreme groups-psychologists and physicists. Define a potential contrarian situation as a situation when the price for asset $S$ is strictly higher than the a priori price of $S$ and the subject receives a signal in favor of $S$, where $S \in\{A, B\}$. It turns out that in potential contrarian situations, psychologists act more often like actual contrarians than physicists do (in 59 percent of potential contrarian situations versus 39 percent for physicists). And this is not due to the fact that psychologists are more likely to trade against their signal in general. In fact, in noncontrarian situations, psychologists trade against their signal in only 15 percent of cases (versus 17 percent for physicists).

\section{H. Are Consultants Different?}

A common (and justified) critique against experiments in economics is that, with few ex- ceptions, they rely on a subject pool consisting only of economics students. While this can be changed with relatively little effort, the reliance on students in general is often dictated by financial and practical constraints. This makes it all the more important that outside validity is checked when one has the rare opportunity to conduct experiments with professionals in business. We were able to conduct the experiment on the same platform with 267 McKinsey consultants. ${ }^{47}$ Do their results differ?

Originally we used a different text version in the control experiment. ${ }^{48}$ To verify whether consultants behaved differently, all four combinations of general subject pool/consultants and old text/new text were played in treatment $P+$ $D$ and probability combination 55-60 (which was the only probability combination played in the control treatment with consultants). Table 12 shows average ruck for these combinations. For both text versions, the consultants have slightly higher values of ruck but none of the differences is significant at the 5-percent level

\footnotetext{
${ }^{47}$ The group size in this control experiment was always limited to ten, and sometimes five. Testing revealed, however, that this has no significant effect.

48 The new text was more precise about the independence of the investment bankers' tips. In the general phase, the two different text versions did not yield significantly different results, and hence the groups with old text were always included in the previous results.
} 
TAble 12-Average ruck of General SubJect PoOL AND CONSULTANTS

\begin{tabular}{lcc}
\hline \hline & General subject pool & Consultants \\
\hline Old text & 0.53 & 0.54 \\
& $(0.09)$ & $(0.17)$ \\
\hline New text & 0.56 & 0.58 \\
& $(0.14)$ & $(0.12)$ \\
\hline
\end{tabular}

Notes: Treatment $P+D$ and probability combination 5560. Standard deviations are given in parentheses. The number of groups are: general/old text: 8 ; consultants/old text: 9 ; general/new text: 18 ; consultants/new text: 6 .

of a MWU-test (two-sided). Thus, the control group of consultants does not behave significantly different from our general subject pool.

\section{Conclusion}

In this paper, we present results of a largescale Internet experiment based on a sequential asset market with privately informed traders. Avery and Zemsky (1998) predict that in such markets, herd behavior should not be observed because all trade decisions are immediately incorporated into the market price which, consequently, reflects all public information. And, indeed, as predicted, we do not find evidence for herding or imitative behavior in our experiment. In contrast to theory, however, subjects do not always follow their private information, but frequently act as contrarians, i.e., they trade against the market and their own signal. To explain this behavior, we study an error model which allows for the possibility that subjects have doubts about the rationality of others and consequently mistrust their decisions. The error model is able to rationalize contrarian behavior at relatively low or high prices. In fact, a very successful strategy in the price treatments would have been to follow one's signal for moderate prices and to be a contrarian for high prices. The fact that contrarian behavior occurs even in our error treatments $P f+D-N$ and $P \beta+D-N$, and in treatments $P-N+\mathrm{AS}$, however, suggests that it cannot be fully explained by an optimal response to errors.

Our experiment complements a large empirical literature on herding. Our results confirm the finding of the bulk of this literature that herd behavior driven by informational externalities does not seem to be an important force in financial markets. To the contrary, one could even argue that the observed contrarian behavior, which we find sometimes to be profitable, has a stabilizing effect as it implies that agents tend to differentiate their investments from those of their predecessors. Of course, this does not rule out herding in financial markets based on explanations other than purely informationbased ones, as, for example, reputation concerns and payoff externalities. To disentangle these factors is an important task for future empirical and experimental research.

\section{REFERENCES}

Allsopp, Louise and Hey, John D. "Two Experiments to Test a Model of Herd Behavior." Experimental Economics, 2000, 3(2), pp. 121-36.

Anderhub, Vital; Müller, Rudolf and Schmidt, Carsten. "Design and Evaluation of an Economic Experiment via the Internet." Journal of Economic Behavior and Organization, 2001, 46(2), pp. 227-47.

Anderson, Lisa R. and Holt, Charles A. "Information Cascades in the Laboratory." American Economic Review, 1997, 87(5), pp. 84762.

Ashiya, Masahiro and Doi, Takero. "Herd Behavior of Japanese Economists." Journal of Economic Behavior and Organization, 2001, 46(3), pp. 343-46.

Ausubel, Lawrence M. "Partially-Revealing Rational Expectations Equilibrium in a Competitive Economy." Journal of Economic Theory, 1990, 50(1), pp. 93-126.

Avery, Christopher and Zemsky, Peter. "Multidimensional Uncertainty and Herd Behavior in Financial Markets." American Economic Review, 1998, 88(4), pp. 724-48.

Banerjee, Abhijit V. "A Simple Model of Herd Behavior." Quarterly Journal of Economics, 1992, 107(3), pp. 797-817.

Berg, Joyce E.; Daley, Lane; Dickhaut, John and O'Brien, John. "Controlling Preferences for Lotteries on Units of Experimental Exchange." Quarterly Journal of Economics, 1986, 101(2), pp. 281-306.

Bikhchandani, Sushil; Hirshleifer, David and Welch, Ivo. "A Theory of Fads, Fashion, Custom, and Cultural Change in Informational 
Cascades." Journal of Political Economy, 1992, 100(5), pp. 992-1026.

Bikhchandani, Sushil and Sharma, Sunil. "Herd Behavior in Financial Markets: A Review." IMF Policy Working Papers, WP/00/48, 2000.

Bikhchandani, Sushil; Hirshleifer, David and Welch, Ivo. "A Theory of Fads, Fashion, Custom, and Cultural Change as Information Cascades." Journal of Political Economy, 1992, 100(5), pp. 992-1026.

Black, Fischer. "Noise." Journal of Finance, 1986, 41(3), pp. 529-43.

Bosch-Domenech, Antoni; Montalvo, José; Nagel, Rosemarie and Satorra, Albert. "One, Two, (Three), Infinity ... : Newspaper and Lab Beauty-Contest Experiments." American Economic Review, 2002, 92(5), pp. 1687-1701.

Bounmy, Kene; Vergnaud, Jean-Christophe; Willinger, Marc and Ziegelmeyer, Anthony. "Information Externalities and Learning with Sequential Interactions," in Patrick Cohendet, Patrick Llerena, Hubert Stahn and Gisele Umbhauer, eds., The economics of networks: Interaction and behaviours. Berlin: SpringerVerlag, 1998, pp. 307-24.

Brunnermeier, Markus K. Asset pricing under asymmetric information: Bubbles, crashes, technical analysis, and herding. Oxford: Oxford University Press, 2001.

Camerer, Colin F. and Hogarth, Robin M. "The Effects of Financial Incentives in Experiments: A Review and Capital-Labor-Production Framework." Journal of Risk and Uncertainty, 1999, 19(1-3), pp. 7-42.

Charness, Gary; Haruvy, Ernan and Sonsino, Doron. "Social Distance and Reciprocity: The Internet vs. the Laboratory." University of California at Santa Barbara, UC Santa Barbara Economics Working Paper Series: No. 1045, 2001.

Cipriani, Marco and Guarino, Antonio. "Herd Behavior and Contagion in Financial Markets." Unpublished Paper, 2001.

Cipriani, Marco and Guarino, Antonio. "Herd Behavior in a Laboratory Financial Market." American Economic Review, 2005 95(5), pp. TK.

Daniel, Kent; Hirshleifer, David and Teoh, Siew Hong. "Investor Psychology in Capital Markets: Evidence and Policy Implications." Journal of Monetary Economics, 2002, 49(1), pp. 139-209.
Diamond, Douglas W. and Dybvig, Philip $\mathbf{H}$. "Bank Runs, Deposit Insurance, and Liquidity." Journal of Political Economy, 1983, 91(3), pp. 401-19.

Dow, James and Gorton, Gary. "Noise Trading, Delegated Portfolio Management, and Economic Welfare." Journal of Political Economy, 1997, 105(5), pp. 1024-50.

Drehmann, Mathias; Oechsller, Jörg and Roider, Andreas. "Herding with and without Payoff Externalities-An Internet Experiment." University of Bonn, Bonn Economic Discussion Papers: No. 15, 2004.

Dreman, David. Contrarian investment strategy. New York: Random House, 1979.

Dreman, David. Contrarian investment strategies: The next generation. New York: Simon \& Schuster, 1998.

Forsythe, Robert; Nelson, Forrest; Neumann, George A. and Wright, Jack. "Anatomy of an Experimental Political Stock Market." American Economic Review, 1992, 82(5), pp. 1142-61.

Forsythe, Robert; Rietz, Thomas A. and Ross, Thomas W. "Wishes, Expectations and Actions: A Survey on Price Formation in Election Stock Markets." Journal of Economic Behavior and Organization, 1999, 39(1), pp. 83-110.

Glosten, Lawrence R. and Milgrom, Paul R. "Bid, Ask, and Transaction Prices in a Specialist Market with Heterogeneously Informed Traders." Journal of Financial Economics, 1985, 14(1), pp. 71-100.

Goidel, Robert K. and Shields, Todd G. "The Vanishing Marginals, the Bandwagon, and the Mass Media." The Journal of Politics, 1994, 56(3), pp. 802-10.

Graham, John R. "Herding among Investment Newsletters: Theory and Evidence." Journal of Finance, 1999, 54(1), pp. 237-68.

Greiner, Ben; Jacobsen, Hans-Arno and Schmidt, Carsten. "The Virtual Laboratory Infrastructure of Online Economic Experiments," in Kurt Kremer and Volker Macho, eds., Forschung und Wissenschaftliches Rechnen 2002: Beiträge zum Heinz-Billing-Preis 2002. Göttingen: Gesellschaft für Wissenschaftliche Datenverarbeitung, 2003, pp. 5973.

Güth, Werner; Schmidt, Carsten and Sutter, Matthias. "Fairness in the Mail and Opportunism on the Internet: A Newspaper Experiment on 
Ultimatum Bargaining." German Economic Review, 2003, 4(2), pp. 243-65.

Hey, John D. and Morone, Andrea. "Do Markets Drive out Lemmings - or Vice Versa?" Economica, 2004, 71(284), pp. 637-59.

Hirshleifer, David and Teoh, Siew Hong. "Herd Behaviour and Cascading in Capital Markets: A Review and Synthesis." European Financial Management, 2003, 9(1), pp. 2566.

Holt, Charles A. Markets, Games, and Strategic Behavior. Boston: Addison Wesley (forthcoming).

Hommes, Cars H.; Sonnemans, Joep; Tuinstra, Jan and van de Velden, Henk. "Expectations and Bubbles in Asset Pricing Experiments." University of Amsterdam, CeNDEF Working Paper Series: No. 02-05, 2002.

Huck, Steffen and Oechssler, Jörg. "Informational Cascades in the Laboratory: Do They Occur for the Right Reasons?" Journal of Economic Psychology, 2000, 21(6), pp.66171.

Hung, Angela A. and Plott, Charles R. "Information Cascades: Replication and an Extension to Majority Rule and Conformity-Rewarding Institutions." American Economic Review, 2001, 91(5), pp. 1508-20.

Krämer, Carlo; Nöth, Markus and Weber, Martin. "Information Aggregation with Costly Information and Random Ordering: Experimental Evidence." Journal of Economic Behavior and Organization (forthcoming).

Kübler, Dorothea and Weizsäcker, Georg. "Limited Depth of Reasoning and Failure of Cascade Formation in the Laboratory." Review of Economic Studies, 2004, 71(2), pp. 425-41.

La Porta, Rafael; Lakonishok, Josef; Shleifer, Andrei and Vishny, Robert. "Good News for Value Stocks: Further Evidence on Market Efficiency." Journal of Finance, 1997, 52(2), pp. 859-74.

Lakonishok, Josef; Shleifer, Andrei and Vishny, Robert W. "The Impact of Institutional Trading on Stock Prices." Journal of Financial Economics, 1992, 32(1), pp. 23-43.

Lakonishok, Josef; Shleifer, Andrei and Vishny, Robert W. "Contrarian Investment, Extrapolation, and Risk." Journal of Finance, 1994, 49(5), pp. 1541-78.

Lucking-Reiley, David. "Using Field Experiments to Test Equivalence between Auction
Formats: Magic on the Internet." American Economic Review, 1999, 89(5), pp. 106380.

McKelvey, Richard D. and Palfrey, Thomas R. "Quantal Response Equilibria for NormalForm Games." Games and Economic Behavior, 1995, 10(1), pp. 6-38.

McKelvey, Richard D. and Palfrey, Thomas R. "Quantal Response Equilibria for Extensive Form Games." Experimental Economics, 1998, 1(1), pp. 9-41.

Nöth, Markus; Camerer, Colin F.; Plott, Charles R. and Weber, Martin. "Information Aggregation in Experimental Asset Markets: Traps and Misaligned Beliefs." California Institute of Technology, Division of the Humanities and Social Sciences Working Papers: No. 1060, 1999.

Nöth, Markus and Weber, Martin. "Information Aggregation with Random Ordering: Cascades and Overconfidence." Economic Journal, 2003, 113(484), pp. 166-89.

Oberhammer, Clemens and Stiehler, Andreas. "Does Cascade Behavior in Information Cascades Reflect Bayesian Updating? An Experimental Study." Humboldt Universitaet, Berlin, Sonderforschungsbereich 373, Paper: No. 2001-32, 2001.

Plott, Charles R.; Wit, Jorgen and Yang, Winston C. "Parimutuel Betting Markets as Information Aggregation Devices: Experimental Results." Economic Theory, 2003, 22(2), pp. 311-51.

Roth, Alvin E. and Malouf, Michael. "GameTheoretic Models and the Role of Information in Bargaining." Psychological Review, 1979, 86(6), pp. 574-94.

Sadiraj, Klarita; Schram, Arthur and van Wijnbergen, Sweder. "Rational Behavior vs. Herd Behavior: Theoretical and Experimental Analysis." Unpublished Paper, 1999.

Scharfstein, David S. and Stein, Jeremy C. "Herd Behavior and Investment." American Economic Review, 1990, 80(3), pp. 465-79.

Shavit, Tal; Sonsino, Doron and Benzion, Uri. "A Comparative Study of Lotteries Evaluation in Class and on the Web." Journal of Economic Psychology, 2001, 22(4), pp. 483-91.

Sunder, Shyam. "Experimental Asset Markets: A Survey," in John H. Kagel and Alvin E. Roth, eds., The handbook of experimental economics. Princeton: Princeton University Press, 1995, pp. 445-500. 
Welch, Ivo. "Sequential Sales, Learning, and Cascades." Journal of Finance, 1992, 47(2), pp. 695-732.

Welch, Ivo. "Herding among Security Analysts." Journal of Financial Economics, 2000, 58(3), pp. 369-96.

Willinger, Marc and Ziegelmeyer, Anthony. "Are
More Informed Agents Able to Shatter Information Cascades in the Lab?" in Patrick Cohendet, Patrick Llerena, Hubert Stahn and Gisele Umbhauer, eds., The economics of networks: Interaction and behaviours. Heidelberg and New York: Springer, 1998, pp. 291-305. 